\title{
Núcleo ampliado de saúde da família e atenção básica (NASF-AB): um estudo avaliativo sobre suas ações com hipertensos e diabéticos NASF-AB: um estudo avaliativo
}

\author{
Extended family health and basic care center (nasf-ab): an evaluative study on your actions \\ with hypertensive and diabetic \\ Nasf-ab: a study evaluation
}

\author{
Adenilson da Silva Gomes ${ }^{1}$ \\ Orcid: https://orcid.org/0000-0001-6174-2516 \\ Eduarda Ângela Pessoa Cesse ${ }^{3}$ \\ Orcid: https://orcid.org/0000-0001-5745-3981
Rebecca Soares de Andrade Fonseca dos Santos 5
Orcid: https://orcid.org/0000-0003-4527-2248

Petrônio José de Lima Martelli

Orcid: https://orcid.org/0000-0001-6920-6435

\author{
Mariana Farias Gomes ${ }^{4}$ \\ Orcid: https://orcid.org/0000-0003-0895-432X
}

\section{Maria Bernadete Ribeiro Chagas ${ }^{6}$}

Orcid: https://orcid.org/0000-0002-3371-2608

Juliana Martins Barbosa da Silva Costa ${ }^{7}$

Orcid: https://orcid.org/0000-0002-5809-4156

\begin{abstract}
Resumo
Introdução: a implantação das ações com hipertensos e diabéticos promovidos pelo Núcleo Ampliado de Saúde da Família e Atenção Básica (NASF-AB) é elemento pertinente para estudos avaliativos. Objetivo: avaliar a implantação do NASF-AB em relação às suas ações de alimentação/nutrição e atividade física/práticas corporais na atenção a hipertensos e diabéticos na estratégia de saúde da família (ESF) de Petrolina - PE. Metodologia: Trata-se de um estudo avaliativo de análise de implantação do tipo $1 \mathrm{~b}$, que identificou o grau de implantação (GI) do NASF-AB e a influência de atores contextuais políticos e estruturais. Resultados: Foi verificado que o GI e suas dimensões de estrutura e processo estavam parcialmente implantados. Ao analisar o contexto, verificou-se que o mesmo foi favorável à implantação de forma que a abordagem política foi mais favorável do que a abordagem estrutural. Por sua vez, o processo do NASF-AB foi influenciado favoravelmente por fatores políticos como conhecimento acerca do NASF-AB, instituição de parcerias, ampliação de responsabilidades e inovação nas práticas, entretanto, a estrutura foi influenciada desfavoravelmente por fatores como a estrutura física das unidades de saúde, clima de equipe, vínculos profissionais e investimentos no NASF-AB. Conclusão: A implantação parcial revela a necessidade de superar fortes obstáculos para que essa política consiga induzir melhoras efetivas no cuidado com hipertensos e diabéticos na ESF.

Palavras-chave: avaliação em saúde; diabetes mellitus; hipertensão arterial sistêmica; atenção à saúde
\end{abstract}

\footnotetext{
${ }^{1}$ Universidade Federal de Pernambuco. Programa de Pós-graduação em Saúde Coletiva. Centro de Ciências da Saúde. Recife-PE. Email: adenilsongomes@hotmail.com

${ }^{2}$ Universidade Federal de Pernambuco, Centro de Ciências da Saúde, Departamento de Medicina Social, Recife-PE. E-mail: petroniocarla@uol.com.br

${ }^{3}$ Fundação Oswaldo Cruz, Instituto Aggeu Magalhães, Departamento de Saúde Coletiva, Recife-PE. -mail: educesse@uol.com.br

${ }^{4}$ Fundação Oswaldo Cruz, Instituto Aggeu Magalhães, Departamento de Saúde Coletiva, Recife-PE. E-mail: marianafarias1992@gmail.com

${ }^{5}$ Fundação Oswaldo Cruz, Instituto Aggeu Magalhães, Departamento de Saúde Coletiva, Recife-PE. E-mail:

rebecca_soaresandrade@yahoo.com.br

${ }^{6}$ Fundação Oswaldo Cruz, Instituto Aggeu Magalhães, Departamento de Saúde Coletiva, Recife-PE. E-mail: beribeiro@yahoo.com.br

${ }^{7}$ Universidade Federal de Pernambuco, Centro Acadêmico do Agreste, Caruaru-PE. E-mail : julimartins.costa@gmail.com
} 


\begin{abstract}
Introduction: the implementation of actions with hypertensive and diabetic individuals promoted by the Extended Family Health and Basic Care Center (NASF-AB) is a relevant element for evaluative studies. Objective: to evaluate the implementation of NASF-AB in relation to its actions of food/nutrition and physical activity/body practices in the care of hypertensive and diabetic patients in the family health strategy (ESF) of Petrolina - PE. Methodology: This is an evaluative study of type $1 \mathrm{~b}$ implantation analysis, which identified the degree of implantation (GI) of the NASF-AB and the influence of political and structural contextual factors. Results: It was found that the GI and its structure and process dimensions were partially implemented. When analyzing the context, it was found that it was favorable to implementation so that the political approach was more favorable than the structural approach. In turn, the NASF-AB process was favorably influenced by political factors such as knowledge about the NASF-AB, institution of partnerships, increased responsibilities and innovation in practices, however, the structure was unfavorably influenced by factors such as the physical structure of health units, team climate, professional ties and investments in NASF-AB. Conclusion: The partial implantation reveals the need to overcome strong obstacles so that this policy is able to induce effective improvements in the care of hypertensive and diabetic patients in the ESF.
\end{abstract}

Keywords: health evaluation; diabetes mellitus; systemic arterial hypertension; health care

\section{Introdução}

A alta prevalência da Hipertensão Arterial Sistêmica (HAS) e Diabetes Mellitus (DM) tem relação estreita com estilo de vida da população. Dada à cronicidade dessas condições e à complexidade de seu controle, a Atenção Primária à Saúde (APS) constitui-se no principal nível de atenção a esses pacientes, pois através da Estratégia de Saúde na Família (ESF) se promove ações educativas em saúde voltadas para a mudança de comportamentos, assim como cuidados longitudinais para essas doenças ${ }^{1-4}$.

O estímulo para ações que promovam saúde e qualidade de vida a pacientes com HAS e DM vem surgindo nas últimas décadas com a formulação de políticas e/ou intervenções na APS que acompanham, geralmente, a garantia do atendimento integral e resolutivo das demandas impostas por essas condições ${ }^{3-4}$.

Nessa perspectiva, os Núcleo Ampliado de Saúde da Família e Atenção Básica (NASF-AB) se constituem numa política recente do Ministério da Saúde para apoiar as Equipes de Saúde da Família (EqSF) através de equipes multiprofissionais, proporcionando uma atenção à saúde com maior resolubilidade e ampliando o escopo das ações ${ }^{5}$. Através de profissionais da saúde como nutricionistas, professores de educação física, psicólogos, entre outros encontrados no NASF-AB, há a oportunidade de se melhorar o manejo da HAS e DM. Dessa maneira, o conjunto formado pelas EqSF e o apoio especializado oferecido pelos NASF-AB se apresenta como um alicerce no cuidado em saúde dentro da rede de atenção aos portadores dessas doenças.

O NASF-AB dispõe de nove áreas estratégicas para servir de enfoque em suas ações, mas é notória a importância das ações de alimentação/nutrição $(\mathrm{A} / \mathrm{N})$ e atividade física/práticas corporais $(\mathrm{AF} / \mathrm{PC})$ para os portadores desses agravos. Atualmente, revela-se a necessidade de uma atenção especial para o desenvolvimento de ações nessas áreas por influenciarem a prevenção e controle da HAS e $\mathrm{DM}^{6-7}$. Entretanto, no atual manejo dessas doenças, o que se observa é a inadequação de cuidados sendo prestados em diferentes níveis de atenção à saúde, suscitando a má coordenação dos cuidados e a insatisfação dos usuários ${ }^{8}$.

A partir dessa nova dinâmica de organização dos serviços de saúde e da articulação entre NASF-AB e ESF, faz-se necessário repensar a ação de todos os 
envolvidos (comunidade, profissionais da saúde e gestores) a fim de que ocorra a mudança requerida: efetiva produção de saúde para a população adscrita. Desse modo, busca-se uma pactuação política entre as partes e utilização dos mecanismos adaptativos e de apropriação dos diferentes contextos para a efetiva implantação do NASF-AB ${ }^{9}$.

Assim sendo, os estudos de análise de implantação fornecem métodos e abordagens avaliativas que podem avaliar os enlaces entre a intervenção (programas, políticas, serviços, ações) e seu contexto de inserção na produção dos efeitos, o que se torna particularmente importante quando a intervenção é complexa, com múltiplos componentes sobre os quais o contexto pode interagir de diferentes modos ${ }^{10}$.

Assim, este estudo teve como objetivo avaliar a implantação do NASF$\mathrm{AB}$ em relação às ações de $\mathrm{A} / \mathrm{N}$ e $\mathrm{AF} / \mathrm{PC}$ na atenção ao portador de HAS e DM da ESF de Petrolina - PE.

\section{Materiais e Métodos}

\section{Amostra e tipo de estudo}

Trata-se de um estudo avaliativo de análise de implantação segundo o componente $1 \mathrm{~b}$ proposto por Champagne et $a l^{11}$. Esse tipo de análise permite identificar o grau de implantação de uma intervenção em função das características contextuais. Realizou-se um estudo de caso único com um único nível de análise ${ }^{11}$ no município de Petrolina-PE.

Petrolina está situada na região sudoeste do Estado de Pernambuco, a 734 $\mathrm{km}$ da capital, na região do semiárido nordestino. Possui uma rede de serviços de saúde que preza pelo desenvolvimento da
ESF, com o NASF-AB implantado há sete anos. Esse município se constitui em importante centro para a organização da saúde no estado de Pernambuco ${ }^{12}$.

Vale salientar que o estudo esteve vinculado ao projeto intitulado "Núcleo de Apoio à Saúde da Família (NASF-AB): uma análise dos componentes alimentação, nutrição e atividade física na rede de atenção aos hipertensos e diabéticos em Pernambuco", executado pelo grupo de pesquisa do Laboratório de Avaliação, Monitoramento e Vigilância em Saúde (LAM-SAÚDE) do Instituto Aggeu Magalhães da Fundação Oswaldo Cruz (FIOCRUZ) - Pernambuco. Esse projeto, ao qual este estudo está atrelado, foi submetido e aprovado pelo Comitê de Ética em Pesquisas do IAM/Fiocruz-Pernambuco (Parecer $\mathrm{N}^{\circ}$ 1.644.126) sendo sua execução obedecente às normas que regem as pesquisas com seres humanos.

\section{Delineamento da pesquisa}

Foram construídos e validados o Modelo Lógico - ML da intervenção e a Matriz de Análise e Julgamento (MAJ) na qual continha uma série de indicadores para avaliação do grau de implantação (GI) e suas dimensões estrutura e processo do NASF-AB em relação às ações de alimentação, nutrição e atividade física/práticas corporais. A partir da MAJ foram construídos questionários estruturados. A avaliação do contexto foi baseada no modelo político e contingente formulado por Denis e Champagne ${ }^{13}$ na qual foi construído o roteiro semiestruturado para coleta dos dados contextuais. 
Núcleo ampliado de saúde da família e atenção básica (NASF-AB): um estudo avaliativo sobre suas ações com hipertensos e diabéticos NASF-AB: um estudo avaliativo

Extended family health and basic care center (nasf-ab): an evaluative study on your actions with hypertensive and diabetic Nasf-ab: a study evaluation Figura 1 - Modelo Lógico resumido do NASF-AB em relação às ações de alimentação, nutrição e atividade física/práticas corporais.

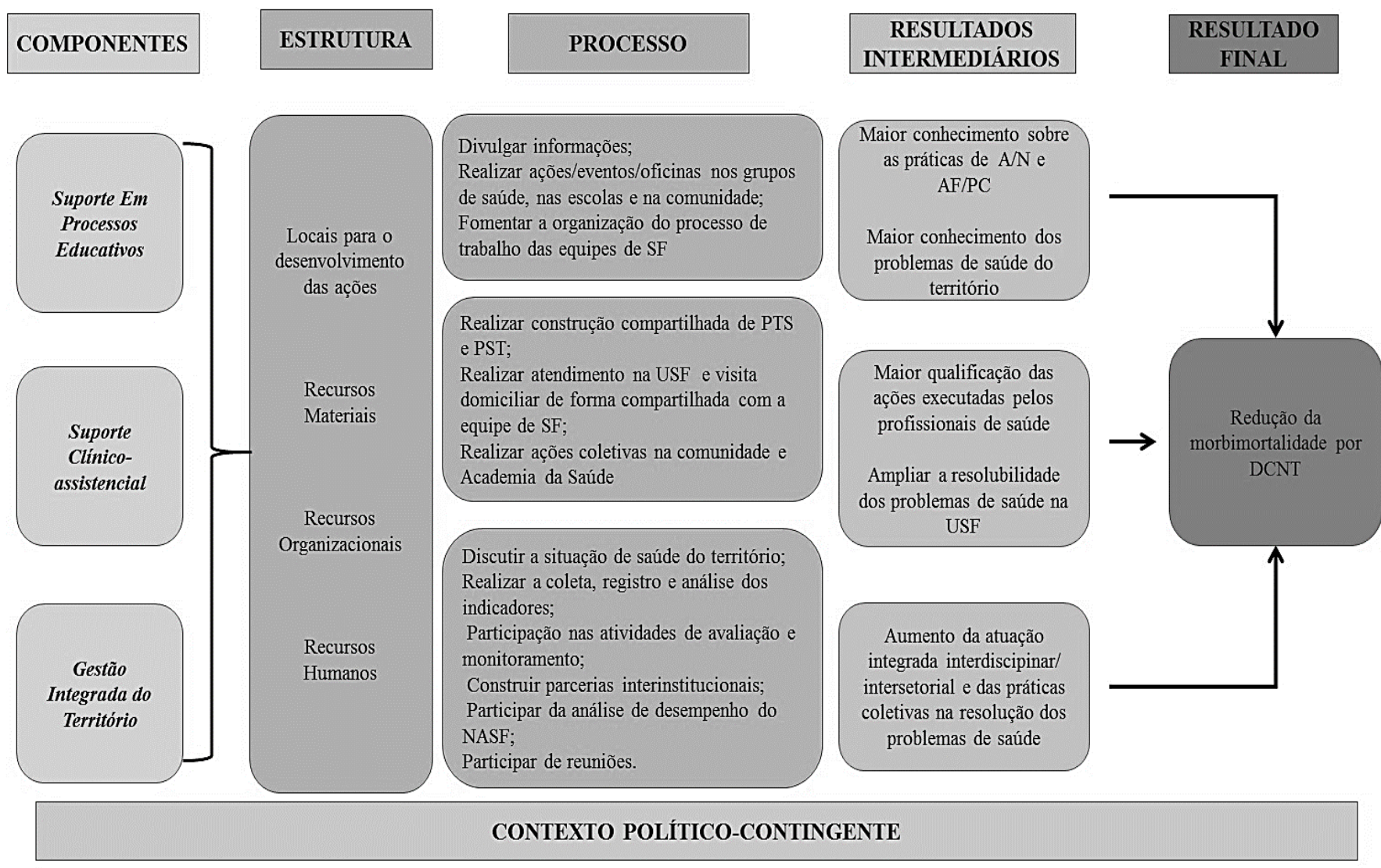

Fonte: Baseado no ML do projeto de pesquisa com referência em Lira ${ }^{16}$.

Legenda: SF - Saúde da Família; A/N - Alimentação e Nutrição; AF/PC - Atividade Física/Práticas Corporais; PTS - Projeto Terapêutico Singular; PST - Projeto Saúde no Território; USF - Unidade de Saúde da Família; DCNT - Doença Crônica Não Transmissível

\section{Critérios de Inclusão e Exclusão}

Por se tratar de estudo de caso, a inclusão e a exclusão de participantes da pesquisa se condicionaram a sua potencialidade de contribuição à coleta de dados. Nesse sentido, selecionaram-se todas as equipes NASF-AB em Petrolina e sua equipe de gestores e coordenação de atenção básica, além de alguns profissionais da ESF.

\section{Procedimentos}

A partir da MAJ foram construídos questionários estruturados para avaliação de estrutura e processo. $\mathrm{Na}$ estrutura, foram avaliados os locais para o desenvolvimento das ações do NASF-AB, os recursos materiais, os recursos organizacionais e os recursos humanos, correspondendo um quantitativo de 18 indicadores da MAJ. No que se refere ao processo, foram avaliadas todas as ações do NASF-AB no que diz respeito à $\mathrm{A} / \mathrm{N}$ e $\mathrm{AF} / \mathrm{PC}$ para usuários hipertensos e diabéticos agrupando-as em três componentes nessa dimensão: suporte em processos educativos (16 indicadores), suporte clínico-pedagógico (14 indicadores) e gestão integrada do território (22 indicadores), totalizando 52 indicadores.

Nessa etapa foi aplicado o questionário estruturado a oito nutricionistas e um educador físico do 
NASF-AB em Petrolina, abrangendo as nove equipes existentes.

Para calcular o GI das dimensões estrutura e processo foi realizado o somatório das pontuações obtidas nos indicadores de cada dimensão separadamente, dividido pela pontuação esperada para a dimensão, e depois multiplicado por 100. O GI total (estrutura
+ processo) foi estabelecido de forma ponderada, por considerar que a dimensão processo era mais importante que a dimensão estrutura na implantação do NASF-AB em relação às áreas em estudo. Nesse sentido, foi atribuído peso quatro para a dimensão estrutura e peso seis para processo. Assim, o GI total foi obtido a partir da seguinte equação ${ }^{\mathbf{1}}$ :

$$
\text { GI Total }=\left(\frac{\left(4 \sum E^{1}+6 \sum P^{1}\right) / 10}{\left(4 \sum E^{2}+6 \sum P^{2}\right) / 10}\right) * 100
$$

${ }^{1}$ Em que $\Sigma \mathrm{E}^{1}=$ Somatório das pontuações obtidas nos indicadores que compunham a dimensão estrutura; $\Sigma \mathrm{P}^{1}=$ Somatório das pontuações obtidas nos indicadores que compunham a dimensão processo; $\Sigma \mathrm{E}^{2}=$ Somatório das pontuações esperadas nos indicadores que compunham a dimensão estrutura; e $\Sigma \mathrm{P}^{2}=$ Somatório das pontuações esperadas nos indicadores que compunham a dimensão processo.

O julgamento de valor considerou os seguintes pontos de corte: $<25,0 \%$ - não implantado; de $25,1 \%$ a $50,0 \%$ implantação incipiente; de 50,1\% a 75,0\% parcialmente implantado; e $>75,1 \%$ implantado ${ }^{14}$.

$\mathrm{Na}$ etapa de avaliação do contexto, os roteiros foram aplicados a dois profissionais da gestão municipal de saúde (Diretoria da Atenção Primária e Coordenação do NASF$\mathrm{AB}$ ), dois médicos e dois enfermeiros da ESF, um agente comunitário de saúde e cinco profissionais do NASF-AB.

Após coleta de dados e leitura das entrevistas oriundas da aplicação dos roteiros semiestruturados, lançou-se mão de uma análise de conteúdo proposta por Bardin $^{15}$, criando-se, assim, categorias temáticas que pudessem contribuir para identificar a influência do contexto político e estrutural de Petrolina no GI do NASFAB. Elas foram criadas da maneira como se apresenta abaixo.

Para cada relato, permitiu-se a criação de núcleos de sentido positivos e negativos. Concluiu-se que o contexto da categoria temática era favorável quando o número de núcleos positivos era maior que os núcleos negativos e vice-versa para as desfavoráveis. $\mathrm{O}$ contexto final era favorável quando o número de categorias temáticas favoráveis era maior que as categorias desfavoráveis (número de categorias favoráveis maior que 50,0\%) e vice-versa. Em caso de empate, o critério de desempate foi o julgamento de importância das categorias temáticas para a implantação da intervenção.

Sete categorias para cada contexto foram criadas, a saber:

- Político: modos de cooperação entre os atores; conhecimento acerca do trabalho do NASF-AB; ampliação das responsabilidades no cuidado ao portador de HAS e DM; mecanismos de parcerias para a realização de ações de $\mathrm{A} / \mathrm{N}$ e AF/PC; participação da gestão nas ações de $\mathrm{A} / \mathrm{N}$ e $\mathrm{AF} / \mathrm{PC}$ do NASF-AB; planejamento e monitoramento das ações de $\mathrm{A} / \mathrm{N}$ e $\mathrm{AF} / \mathrm{PC}$ do NASF-AB; inovação nas práticas.

- Contingente (estrutural): atributos dos gestores; ambiente de trabalho do NASF-AB; vínculos profissionais; recursos financeiros; clima de equipe; estruturas físicas das unidades de saúde da família para atuação do NASF-AB; formalização do trabalho do 
Núcleo ampliado de saúde da família e atenção básica (NASF-AB): um estudo avaliativo sobre suas ações com hipertensos e diabéticos NASF-AB: um estudo avaliativo

Extended family health and basic care center (nasf-ab): an evaluative study on your actions with hypertensive and diabetic Nasf-ab: a study evaluation

NASF-AB frente às ações de $\mathrm{A} / \mathrm{N}$ e $\mathrm{AF} / \mathrm{PC}$.

Após a determinação do contexto, foi verificada a sua influência sobre o grau de implantação analisando as possíveis relações existentes entre si através de uma triangulação de dados.

\section{Resultados}

Grau de implantação do NASF-AB em relação às ações de alimentação, nutrição $e$ atividade física/práticas corporais no município de Petrolina

O GI total do NASF-AB em relação à alimentação, nutrição e atividade física/práticas corporais no município de Petrolina, encontra-se parcialmente implantado recebendo uma pontuação percentual de $58,8 \%$.

\section{$\underline{\text { Grau de Implantação de Estrutura }}$}

Figura 2 - Quadro da pontuação (\%) por critério e indicador da dimensão estrutura do NASF-AB no município de Petrolina.

\begin{tabular}{|c|c|c|c|c|}
\hline DIMENSÃO & CRITÉRIO & INDICADOR & $\begin{array}{l}\text { PONTUAÇÃO } \\
\text { ATINGIDA } \\
\text { (\%) }\end{array}$ & $\begin{array}{l}\text { SUBTOTAL } \\
\text { DO } \\
\text { CRITÉRIO } \\
(\%) \\
\end{array}$ \\
\hline \multirow{7}{*}{ 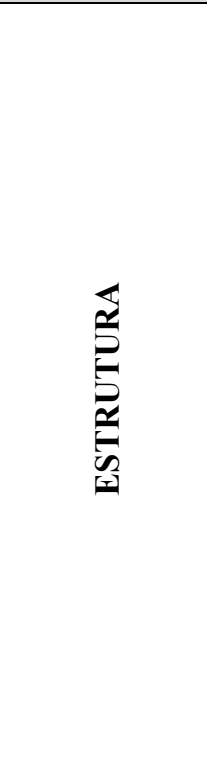 } & $\begin{array}{l}\text { Local para } \\
\text { realizar reunião }\end{array}$ & $\begin{array}{l}\% \text { de USF sob área de abrangência do } \\
\text { NASF-AB que possuam local para realizar } \\
\text { reunião }\end{array}$ & 59,3 & 59,3 \\
\hline & $\begin{array}{l}\text { Local para } \\
\text { realizar as ações } \\
\text { com a } \\
\text { comunidade }\end{array}$ & $\begin{array}{l}\text { \% de USF sob área de abrangência do } \\
\text { NASF-AB que possuam local na } \\
\text { USF/SMS/comunidade para realizar as ações } \\
\text { com a comunidade }\end{array}$ & 77,8 & 77,8 \\
\hline & $\begin{array}{l}\text { Material para as } \\
\text { ações }\end{array}$ & Existência de materiais de escritório & 55,6 & 55,6 \\
\hline & \multirow{2}{*}{$\begin{array}{l}\text { Material } \\
\text { informativo }\end{array}$} & $\begin{array}{l}\text { Existência de material informativo } \\
\text { relacionado a temática de } \mathrm{A} / \mathrm{N}\end{array}$ & 55,6 & \multirow{2}{*}{44,4} \\
\hline & & $\begin{array}{l}\text { Existência de material informativo } \\
\text { relacionado a temática de AF/PC }\end{array}$ & 33,3 & \\
\hline & \multirow{2}{*}{ Fichas do e-SUS } & $\begin{array}{l}\text { \% de USF sob área de abrangência do } \\
\text { NASF-AB que exista Ficha de Atividade } \\
\text { Individual }\end{array}$ & 80,6 & \multirow{2}{*}{89,8} \\
\hline & & $\begin{array}{l}\% \text { de USF sob área de abrangência do } \\
\text { NASF-AB que exista Ficha de Atividade } \\
\text { Coletiva }\end{array}$ & 88,9 & \\
\hline
\end{tabular}




\begin{tabular}{|c|c|c|c|}
\hline & $\begin{array}{l}\text { \% de USF sob área de abrangência do } \\
\text { NASF-AB que exista Ficha de } \\
\text { Procedimentos }\end{array}$ & 100,0 & \\
\hline Prontuários & $\begin{array}{l}\text { \% de USF sob área de abrangência do } \\
\text { NASF-AB que dispõe prontuários dos } \\
\text { usuários para uso do NASF-AB }\end{array}$ & 77,8 & 77,8 \\
\hline Equipamentos & Existência de equipamentos & 55,6 & 55,6 \\
\hline $\begin{array}{l}\text { Computador } \\
\text { com internet }\end{array}$ & $\begin{array}{l}\text { \% de USF sob área de abrangência do } \\
\text { NASF-AB que possuem computadores com } \\
\text { internet para uso do NASF-AB }\end{array}$ & 55,6 & 55,6 \\
\hline Veículo & Existência de veículo & 11,1 & 11,1 \\
\hline $\begin{array}{c}\text { Protocolo de } \\
\text { fluxo de } \\
\text { encaminhamento }\end{array}$ & $\begin{array}{l}\text { \% de USF sob área de abrangência do } \\
\text { NASF-AB que tenham protocolo de fluxo de } \\
\text { encaminhamento }\end{array}$ & 77,8 & 77,8 \\
\hline $\begin{array}{c}\text { Cadernos de } \\
\text { Atenção Básica }\end{array}$ & $\begin{array}{l}\text { \% de USF sob área de abrangência do } \\
\text { NASF-AB que tenham Cadernos de Atenção } \\
\text { Básica }\end{array}$ & 38,9 & 38,9 \\
\hline $\begin{array}{l}\text { Instrumento para } \\
\text { realizar o } \\
\text { diagnóstico do } \\
\text { território } \\
\end{array}$ & $\begin{array}{l}\text { Possui o instrumento (método, autor de } \\
\text { referência, etc) para realizar o diagnóstico do } \\
\text { território }\end{array}$ & 33,3 & 33,3 \\
\hline \multirow{3}{*}{$\begin{array}{l}\text { Equipe do } \\
\text { NASF-AB } \\
\text { qualificada }\end{array}$} & $\begin{array}{l}\text { \% de profissionais do NASF-AB que } \\
\text { receberam qualificação/capacitação na } \\
\text { temática de } \mathrm{A} / \mathrm{N} \text { nos últimos dois anos }\end{array}$ & 44,4 & \multirow{3}{*}{50,6} \\
\hline & $\begin{array}{l}\text { \% de profissionais do NASF-AB que } \\
\text { receberam qualificação/capacitação na } \\
\text { temática de } \mathrm{AF} / \mathrm{PC} \text { nos últimos dois anos }\end{array}$ & 18,5 & \\
\hline & $\begin{array}{l}\text { Existência de nutricionista e educador físico } \\
\text { na equipe NASF-AB }\end{array}$ & 88,9 & \\
\hline \multicolumn{3}{|c|}{ TOTAL DA DIMENSÃO ESTRUTURA } & 59,3 \\
\hline
\end{tabular}

Fonte: elaboração própria

TOTAL DA DIMENSÃO ESTRUTURA

Legenda: A/N - Alimentação, nutrição; AF/PC - atividade física/práticas corporais; USF -

Unidade de Saúde da Família; SMS - Secretaria Municipal de Saúde; NASF-AB - Núcleo de Apoio à Saúde da Família; e-SUS - Sistema eletrônico do SUS.

\section{Grau de Implantação de Processo}

A dimensão processo foi classificada como parcialmente implantada, tendo em vista sua pontuação percentual de $58,7 \%$, conforme apontada no quadro da Figura 3.

Todos os componentes da dimensão processo foram considerados parcialmente implantados, recebendo as seguintes pontuações: Suporte em Processos Educativos - 62,7\%; Suporte ClínicoPedagógico - 61,5\%; Gestão Integrada do Território $-52,3 \%$.
No componente 'Suporte em Processos Educativos' apenas os critérios "divulgação de informações" e "apoio a grupos de saúde" foram considerados implantados. "Realização de oficinas com a equipe de saúde da família e a comunidade" e "orientação referente ao processo de trabalho das equipes de saúde da família referentes à temática em estudo" consideraram-se com implantação incipiente (Figura 3). 
Núcleo ampliado de saúde da família e atenção básica (NASF-AB): um estudo avaliativo sobre suas ações com hipertensos e diabéticos NASF-AB: um estudo avaliativo

Extended family health and basic care center (nasf-ab): an evaluative study on your actions with hypertensive and diabetic Nasf-ab: a study evaluation

Figura 3 - Quadro da pontuação (\%) por critério, indicador e componente da dimensão processo do NASF-AB no município de Petrolina/PE.

\begin{tabular}{|c|c|c|c|c|c|}
\hline DIMENSÃO & COMPONENTE & CRITÉRIO & INDICADOR & $\begin{array}{l}\text { PONTUAÇÃO } \\
\text { ATINGIDA } \\
(\%)\end{array}$ & $\begin{array}{l}\text { SUBTOTAL } \\
\text { DO } \\
\text { CRITÉRIO } \\
(\%) \\
\end{array}$ \\
\hline \multirow{18}{*}{ 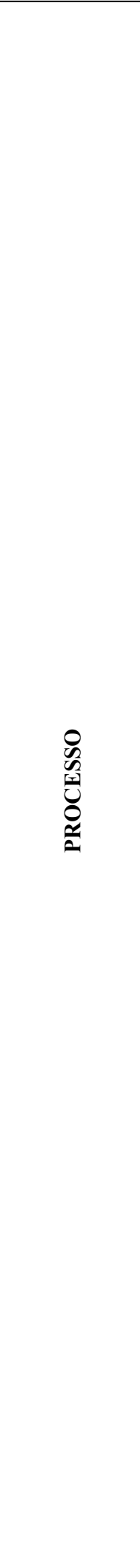 } & \multirow{16}{*}{$\begin{array}{l}\text { Suporte em } \\
\text { processos } \\
\text { educativos }\end{array}$} & \multirow{2}{*}{$\begin{array}{l}\text { Divulgação de } \\
\text { informações sobre A/N } \\
\text { e/ou AF/PC }\end{array}$} & $\begin{array}{l}\text { Periodicidade de divulgação de } \\
\text { informações sobre } \mathrm{A} / \mathrm{N}\end{array}$ & 83,3 & \multirow{2}{*}{81,9} \\
\hline & & & $\begin{array}{l}\text { Periodicidade de divulgação de } \\
\text { informações sobre AF/PC }\end{array}$ & 80,6 & \\
\hline & & \multirow{2}{*}{$\begin{array}{l}\text { Participação do NASF- } \\
\text { AB em eventos } \\
\text { comunitários sobre A/N } \\
\text { e AF/PC }\end{array}$} & $\begin{array}{l}\mathrm{N}^{\circ} \text { eventos comunitários sobre } \mathrm{A} / \mathrm{N} \\
\text { em que o NASF-AB participou no } \\
\text { último ano }\end{array}$ & 77,8 & \multirow{2}{*}{61,1} \\
\hline & & & $\begin{array}{l}\mathrm{N}^{0} \text { eventos comunitários sobre } \mathrm{AF} / \mathrm{PC} \\
\text { em que o NASF-AB participou no } \\
\text { último ano }\end{array}$ & 44,4 & \\
\hline & & \multirow{2}{*}{$\begin{array}{l}\text { Apoio a grupos de saúde } \\
\text { sobre a temática de } \mathrm{A} / \mathrm{N} \\
\text { e } \mathrm{AF} / \mathrm{PC}\end{array}$} & $\begin{array}{l}\% \text { de grupos existentes no território } \\
\text { apoiados pelo NASF-AB referentes a } \\
\text { temática de } \mathrm{A} / \mathrm{N}\end{array}$ & 80,6 & \multirow{2}{*}{76,4} \\
\hline & & & $\begin{array}{l}\text { \% de grupos existentes no território } \\
\text { apoiados pelo NASF-AB referentes a } \\
\text { temática de AF/PC }\end{array}$ & 72,2 & \\
\hline & & \multirow{2}{*}{$\begin{array}{l}\text { Realização de oficinas } \\
\text { com a equipe de SF e a } \\
\text { comunidade para a } \\
\text { construção de materiais } \\
\text { que fomentem a pratica } \\
\text { A/N e AF/PC }\end{array}$} & $\begin{array}{l}\mathrm{N}^{o} \text { de oficinas para construção de } \\
\text { materiais que fomentem a prática de } \\
\mathrm{A} / \mathrm{N} \text { realizadas no último ano }\end{array}$ & 33,3 & \multirow{2}{*}{$33,3 \%$} \\
\hline & & & $\begin{array}{l}\mathrm{N}^{\mathrm{o}} \text { de oficinas para construção de } \\
\text { materiais que fomentem a prática de } \\
\mathrm{AF} / \mathrm{PC} \text { realizadas no último ano }\end{array}$ & 33,3 & \\
\hline & & \multirow{2}{*}{$\begin{array}{l}\text { Orientação para as } \\
\text { famílias através de } \\
\text { material instrucional } \\
\text { com recomendações de } \\
\mathrm{A} / \mathrm{N} \text { e AF/PC }\end{array}$} & $\begin{array}{l}\text { Realização de orientação para as } \\
\text { famílias através de material } \\
\text { instrucional referente a temática de } \\
\text { A/N }\end{array}$ & 100,0 & \multirow{2}{*}{$72,2 \%$} \\
\hline & & & $\begin{array}{l}\text { Realização de orientação para as } \\
\text { famílias através de material } \\
\text { instrucional referente a temática de } \\
\text { AF/PC }\end{array}$ & 44,4 & \\
\hline & & \multirow{2}{*}{$\begin{array}{l}\text { Realização de ações } \\
\text { referentes a } \mathrm{A} / \mathrm{N} \text { e } \\
\mathrm{AF} / \mathrm{PC} \text { nas escolas } \\
\text { existentes no território }\end{array}$} & $\begin{array}{l}\text { Periodicidade de realização de ações } \\
\text { referentes à } \mathrm{A} / \mathrm{N} \text { nas escolas existentes } \\
\text { no território }\end{array}$ & 55,6 & \multirow{2}{*}{55,6} \\
\hline & & & $\begin{array}{l}\text { Periodicidade de realização de ações } \\
\text { referentes à } \mathrm{AF} / \mathrm{PC} \text { nas escolas } \\
\text { existentes no território }\end{array}$ & 55,6 & \\
\hline & & \multirow{2}{*}{$\begin{array}{l}\text { Execução de ações de } \\
\text { educação permanente } \\
\text { referentes à temática de } \\
\mathrm{A} / \mathrm{N} \text { e } \mathrm{AF} / \mathrm{PC}\end{array}$} & $\begin{array}{l}\text { \% de equipes de } \mathrm{SF} \text { em que foram } \\
\text { realizadas ações de educação } \\
\text { permanente referentes à } \mathrm{A} / \mathrm{N} \text { no último } \\
\text { ano }\end{array}$ & 44,4 & \multirow{2}{*}{43,0} \\
\hline & & & $\begin{array}{l}\text { \% de equipes de } \mathrm{SF} \text { em que foram } \\
\text { realizadas ações de educação } \\
\text { permanente referentes à } \mathrm{AF} / \mathrm{PC} \text { no } \\
\text { último ano }\end{array}$ & 41,7 & \\
\hline & & \multirow{2}{*}{$\begin{array}{l}\text { Orientação referente ao } \\
\text { processo de trabalho das } \\
\text { equipes de } \mathrm{SF} \text { referentes } \\
\text { à } \mathrm{A} / \mathrm{N} \text { e } \mathrm{AF} / \mathrm{PC}\end{array}$} & $\begin{array}{l}\text { \% de equipes de SF que receberam } \\
\text { orientações do NASF-AB referentes } \\
\text { ao processo de trabalho das equipes } \\
\text { sobre a temática de } \mathrm{A} / \mathrm{N} \text { no último } \\
\text { ano }\end{array}$ & 72,2 & \multirow{2}{*}{58,3} \\
\hline & & & $\begin{array}{l}\text { \% de equipes de } \mathrm{SF} \text { que receberam } \\
\text { orientações do NASF-AB referentes } \\
\text { ao processo de trabalho das equipes } \\
\text { sobre a temática de } \mathrm{AF} / \mathrm{PC} \text { no último } \\
\text { ano }\end{array}$ & 44,4 & \\
\hline & \multicolumn{4}{|c|}{ SUBTOTAL DO COMPONENTE } & 62,7 \\
\hline & $\begin{array}{l}\text { Suporte Clínico- } \\
\text { pedagógico }\end{array}$ & $\begin{array}{l}\text { Discussão de casos ou } \\
\text { problemas de saúde }\end{array}$ & $\begin{array}{l}\text { \% de equipes de SF que o NASF-AB } \\
\text { realizou discussão de casos ou }\end{array}$ & 77,8 & 70,4 \\
\hline
\end{tabular}




\begin{tabular}{|c|c|c|c|c|}
\hline \multirow[t]{13}{*}{ 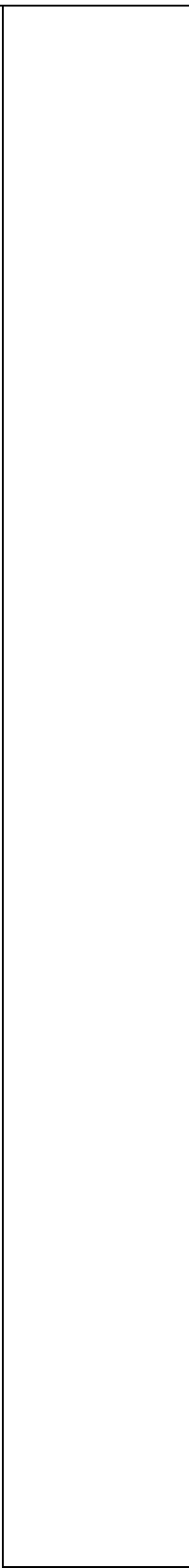 } & $\begin{array}{c}\text { referentes à } \mathrm{A} / \mathrm{N} \text { e } \\
\mathrm{AF} / \mathrm{PC} \text { com a equipe de } \\
\mathrm{SF}\end{array}$ & $\begin{array}{l}\text { problemas de saúde referentes à } \mathrm{A} / \mathrm{N} \\
\text { no último semestre } \\
\% \text { de equipes de SF que o NASF-AB } \\
\text { realizou discussão de casos ou } \\
\text { problemas de saúde referentes à } \\
\text { AF/PC no último semestre }\end{array}$ & 63,0 & \\
\hline & $\begin{array}{l}\text { Construção } \\
\text { compartilhada de } \\
\text { Projeto Terapêutico } \\
\text { Singular (PTS) } \\
\end{array}$ & $\begin{array}{c}\text { \% de equipes de SF que o NASF-AB } \\
\text { participou da construção do PTS no } \\
\text { último semestre }\end{array}$ & 63,0 & 63,0 \\
\hline & $\begin{array}{c}\text { Construção } \\
\text { compartilhada de } \\
\text { Projeto de Saúde no } \\
\text { Território (PST) } \\
\end{array}$ & $\begin{array}{c}\text { \% de equipes de SF que o NASF-AB } \\
\text { participou da construção do PST no } \\
\text { último semestre }\end{array}$ & 0,0 & 0,0 \\
\hline & $\begin{array}{c}\text { Atendimento clínico } \\
\text { compartilhado com os } \\
\text { profissionais da equipe } \\
\text { de SF } \\
\end{array}$ & $\begin{array}{l}\% \text { de equipes de SF que o NASF-AB } \\
\text { participou de atendimento clínico } \\
\text { compartilhado }\end{array}$ & 77,8 & 77,8 \\
\hline & \multirow{2}{*}{$\begin{array}{l}\text { Ações de } \mathrm{A} / \mathrm{N} \text { e } \mathrm{AF} / \mathrm{PC} \\
\text { em conjunto com a } \\
\text { Academia da } \\
\text { Saúde/cidade/similares }\end{array}$} & $\begin{array}{l}\text { Periodicidade de realização de ações } \\
\text { de A/N em conjunto com a Academia } \\
\text { da Saúde/cidade/similares }\end{array}$ & 36,1 & \multirow{2}{*}{33,3} \\
\hline & & $\begin{array}{l}\text { Periodicidade de realização de ações } \\
\text { de AF/PC em conjunto com a } \\
\text { Academia da Saúde/cidade/similares }\end{array}$ & 30,6 & \\
\hline & $\begin{array}{l}\text { Registro das atividades } \\
\text { realizadas nas fichas do } \\
\text { e-SUS }\end{array}$ & $\begin{array}{l}\text { Registro das atividades realizadas nas } \\
\text { fichas do e-SUS }\end{array}$ & 100,0 & 100,0 \\
\hline & $\begin{array}{l}\text { Uso protocolo de fluxo } \\
\text { de encaminhamento }\end{array}$ & $\begin{array}{l}\text { Utilização do protocolo de fluxo de } \\
\text { encaminhamento }\end{array}$ & 77,8 & 77,8 \\
\hline & Uso do prontuário & $\begin{array}{c}\text { Utilização do prontuário pelo NASF- } \\
\text { AB }\end{array}$ & 88,9 & 88,9 \\
\hline & \multirow{2}{*}{$\begin{array}{l}\text { Atendimento domiciliar } \\
\text { individual que envolva } \\
\text { problemas de saúde } \\
\text { referentes à } \mathrm{A} / \mathrm{Ne} \\
\mathrm{AF} / \mathrm{PC}\end{array}$} & $\begin{array}{l}\text { Atendimento domiciliar individual que } \\
\text { envolva problemas de saúde referentes } \\
\text { à } \mathrm{A} / \mathrm{N} \\
\end{array}$ & 88,9 & \multirow{2}{*}{77,8} \\
\hline & & $\begin{array}{l}\text { Atendimento domiciliar individual que } \\
\text { envolva problemas de saúde referentes } \\
\text { à } \mathrm{AF} / \mathrm{PC}\end{array}$ & 66,7 & \\
\hline & \multirow{2}{*}{$\begin{array}{l}\text { Atendimento domiciliar } \\
\text { compartilhado que } \\
\text { envolva problemas de } \\
\text { saúde referentes à } \mathrm{A} / \mathrm{N} \text { e } \\
\text { AF/PC }\end{array}$} & $\begin{array}{c}\text { Atendimento domiciliar compartilhado } \\
\text { com algum integrante da equipe de SF } \\
\text { que envolva problemas de saúde } \\
\text { referentes à } \mathrm{A} / \mathrm{N} \\
\end{array}$ & 88,9 & \multirow{2}{*}{72,2} \\
\hline & & $\begin{array}{c}\text { Atendimento domiciliar compartilhado } \\
\text { com algum integrante da equipe de SF } \\
\text { que envolva problemas de saúde } \\
\text { referentes à } \mathrm{AF} / \mathrm{PC}\end{array}$ & 55,6 & \\
\hline \multicolumn{4}{|c|}{ SUBTOTAL DO COMPONENTE } & 61,5 \\
\hline \multirow{4}{*}{$\begin{array}{l}\text { Gestão } \\
\text { Integrada do } \\
\text { Território }\end{array}$} & $\begin{array}{c}\text { Utilização do } \\
\text { instrumento (método, } \\
\text { autor de referência, etc.) } \\
\text { para realização do } \\
\text { diagnóstico do território } \\
\end{array}$ & $\begin{array}{l}\text { Utiliza o instrumento (método, autor } \\
\text { de referência, etc.) para realização do } \\
\text { diagnóstico do território }\end{array}$ & 33,3 & 33,3 \\
\hline & $\begin{array}{l}\text { Discussão da situação } \\
\text { de saúde do território } \\
\text { com os gestores, } \\
\text { equipes de SF e a } \\
\text { comunidade }\end{array}$ & $\begin{array}{l}\mathrm{N}^{o} \text { de discussões da situação de saúde } \\
\text { do território em conjunto com os } \\
\text { gestores, equipes de } \mathrm{SF} \text { e a } \\
\text { comunidade no último ano }\end{array}$ & 33,3 & 33,3 \\
\hline & \multirow{2}{*}{$\begin{array}{l}\text { Identificação de áreas } \\
\text { geográficas, segmentos } \\
\text { sociais e grupos } \\
\text { populacionais de maior } \\
\text { risco aos agravos } \\
\text { referentes à A/N e } \\
\mathrm{AF} / \mathrm{PC}\end{array}$} & $\begin{array}{l}\text { Identificação de áreas geográficas, } \\
\text { segmentos sociais e grupos } \\
\text { populacionais de maior risco aos } \\
\text { agravos referentes à } \mathrm{A} / \mathrm{N} \text { no último } \\
\text { ano } \\
\end{array}$ & 77,8 & \multirow[t]{2}{*}{61,1} \\
\hline & & $\begin{array}{l}\text { Identificação de áreas geográficas, } \\
\text { segmentos sociais e grupos } \\
\text { populacionais de maior risco aos }\end{array}$ & 44,4 & \\
\hline
\end{tabular}


Núcleo ampliado de saúde da família e atenção básica (NASF-AB): um estudo avaliativo sobre suas ações com

hipertensos e diabéticos NASF-AB: um estudo avaliativo

Extended family health and basic care center (nasf-ab): an evaluative study on your actions with hypertensive and diabetic Nasf-ab: a study evaluation

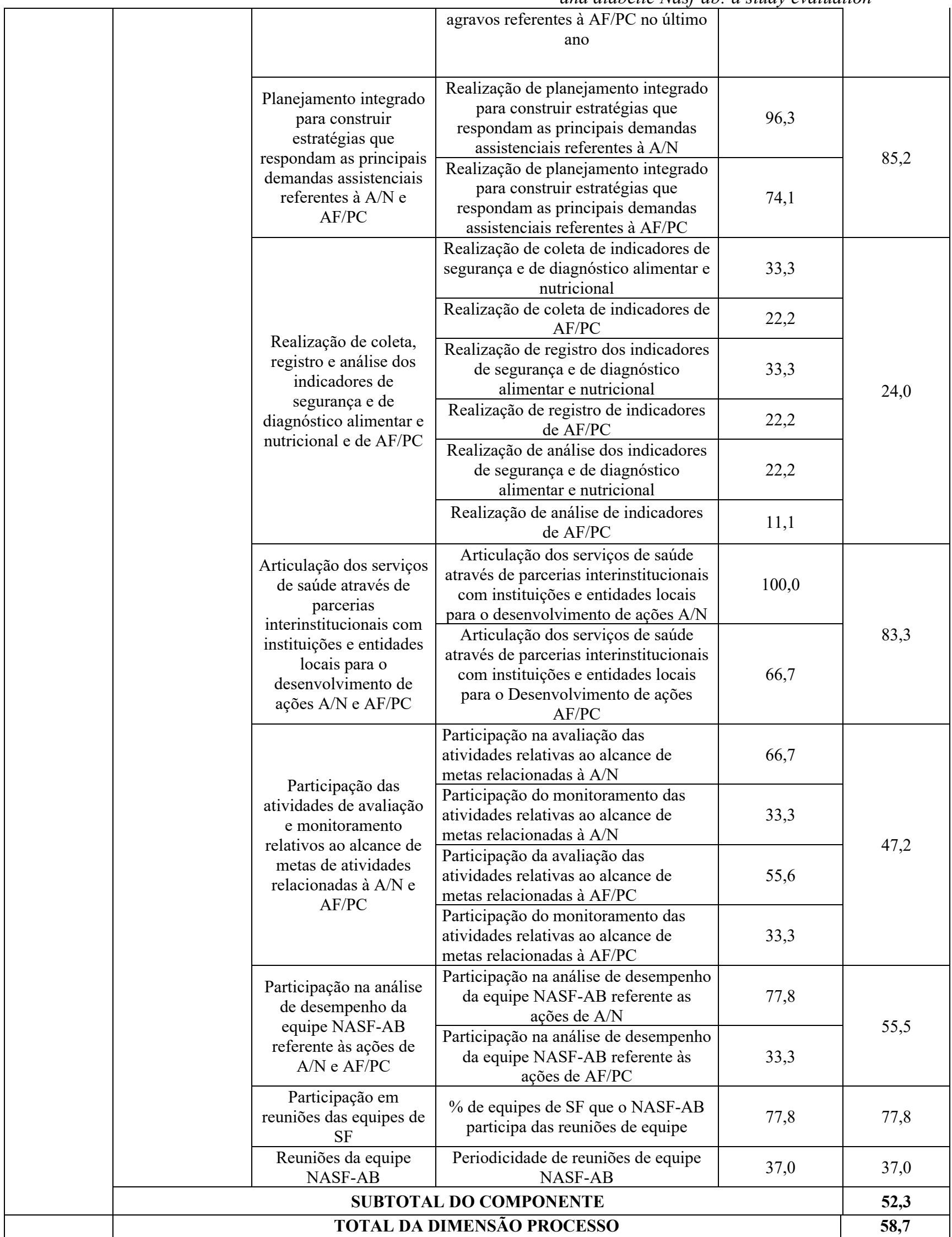

Fonte: elaboração própria

Legenda: A/N - Alimentação, nutrição; AF/PC - atividade física/práticas corporais; NASF-AB - Núcleo de Apoio à Saúde da Família; PTS - Projeto Terapêutico Singular; PST - Projeto de Saúde no Território; e-SUS - Sistema eletrônico do SUS. 
Contexto de implantação do NASF$A B$ em relação às ações de alimentação, nutrição $e$ atividade física/práticas corporais no município de Petrolina

A abordagem política apresentou $57,1 \%$ de categorias favoráveis, classificando-se como favorável à implantação do NASF-AB em relação às ações de alimentação/nutrição e atividade física/práticas corporais no município de Petrolina.

Por outro lado, ao se tratar do contexto estrutural do NASF-AB em relação às ações de $\mathrm{A} / \mathrm{N}$ e $\mathrm{AF} / \mathrm{PC}$ em Petrolina, este foi considerado como desfavorável à sua implantação com 57,1\% de categorias desfavoráveis.

\section{Análise da relação entre o contexto e o grau de implantação do $N A S F-A B$}

A presença de apenas $50 \%$ de categorias favoráveis pode explicar a implantação parcial tanto da estrutura quanto do processo do grau de implantação do NASF-AB em relação às ações de alimentação, nutrição e atividade física/práticas corporais em Petrolina.

\section{Discussão}

Quanto ao grau de implantação da estrutura do NASF-AB, a existência de protocolos de fluxo de encaminhamento, por exemplo, configura-se como um elemento importante para a continuidade do cuidado quando verificados os limites na ESF para a resolubilidade dos problemas de saúde dos usuários com essas doenças crônicas. A articulação dos serviços dentro da Rede de Atenção à Saúde e seus diferentes níveis se fazem necessários para garantir a integralidade das ações de saúde ${ }^{1}$.

Entretanto, observa-se a implantação incipiente de muitos critérios, dos quais destaca-se "equipe NASF-AB qualificada" (Figura 2). Essa fragilidade na qualificação da equipe também foi encontrada nos estudos realizados por Fernandes et al. ${ }^{17} \mathrm{e}$ Reis et al. ${ }^{18}$ ao investigarem o trabalho de profissionais do NASF-AB na APS. Fagundes $^{19}$ ressalta que a falta de capacitação de profissionais dessa equipe pode ferir uma das diretrizes dessa proposta: a educação permanente em saúde aos profissionais e aos usuários, uma vez que o NASF-AB poderia não estar utilizando suas ferramentas de trabalho de forma correta.

Além disso, observa-se que "locais para realizar reunião", "materiais informativos", "equipamentos", "computadores com internet", "veículos", entre outros, também são recursos que configuram uma estrutura fragilizada para o NASF-AB e isso direciona meios para precariedade da proposta no fortalecimento da resolubilidade da atenção básica e do seu papel de coordenação do cuidado na rede de serviços de saúde. Martinez et al..$^{20}$ apontam que em muitas investigações encontram-se indicativos de problemas estruturais, principalmente relacionados à estrutura física das unidades de saúde, ao transporte para os profissionais e à falta de insumos estratégicos.

A implantação parcial da dimensão estrutura do NASF-AB abre debates para a importância dos aspectos estruturais estarem sendo cada vez mais efetivados, pois ela detém de elementos importantes devendo ser considerada no conjunto de prioridades, pois possibilita a construção de ações de saúde efetivas e humanizadas. Assim sendo, a estrutura é um componente que tende a acrescer na qualidade da equipe, organizações e serviços de saúde.

Por sua vez, no grau de implantação do processo, ao olhar simultaneamente para os critérios considerados como implantados e os com implantação incipiente, verifica-se que o NASF-AB possui fragilidades nas práticas educativas. Anjos et al. ${ }^{21}$ trazem essa temática refletindo sobre a importância de se estar fazendo revisões críticas desses processos educativos elaborados pelos 
Núcleo ampliado de saúde da família e atenção básica (NASF-AB): um estudo avaliativo sobre suas ações com hipertensos e diabéticos NASF-AB: um estudo avaliativo

Extended family health and basic care center (nasf-ab): an evaluative study on your actions with hypertensive and diabetic Nasf-ab: a study evaluation

profissionais do NASF-AB para que haja efetivação do seu processo de trabalho com as EqSF, a fim de levar à população uma nova concepção e modo de assistir em saúde.

No componente 'Suporte ClínicoPedagógico' destacam-se os critérios "registro das atividades realizadas nas fichas do e-SUS", o "uso de protocolo de fluxo de encaminhamento", o "atendimento domiciliar individual" e a "utilização de prontuários", pois todos foram classificados como implantados. "Construção compartilhada de Projeto de Saúde no Território" e "ações de alimentação/nutrição e atividade física/práticas corporais em conjunto com a Academia da Saúde/cidade/similares" classificaram-se como não implantados e implantação incipiente, respectivamente (Figura 3).

Esse componente pode ser considerado um importante conjunto de ações que favorecem a indução de apoio matricial, repercutindo diretamente no alcance dos objetivos do NASF-AB ${ }^{22-23}$. A não implantação de diversas atividades do suporte clínico-assistencial, pode estar colaborando para que essa equipe desenvolva ações limitantes, o que repercute em fragilidades na coordenação do cuidado em parceria com as EqSF.

Por fim, no componente 'Gestão Integrada do Território' pode-se observar que os critérios "planejamento integrado" e "articulação dos serviços de saúde através de parcerias interinstitucionais" classificaram-se como implantados. Em contrapartida, a "realização de coleta, registro e análise dos indicadores de segurança e de diagnóstico alimentar e nutricional e de atividade física/práticas corporais" e "reuniões da equipe NASFAB" configuraram-se como não implantado e implantado incipiente, respectivamente (QUADRO 2).

O NASF-AB desempenha o apoio à gestão e à atenção, sendo uma estratégia de organização das práticas de cuidado e de gestão tendo como diretriz a formação de espaços coletivos que subsidiem ações de prevenção e promoção à saúde, intramuros ou territoriais, bem como de planejamento e gestão local ${ }^{24-25}$. Assim, as atividades vistas nesse último componente sendo consideradas como implantadas e parcialmente implantadas podem dar margem à difícil consolidação dessa diretriz.

No que tange à avaliação do contexto em sua abordagem política, percebeu-se que o conhecimento acerca do processo de trabalho do NASF-AB foi uma categoria favorável desse contexto, pois foi identificado que as EqSF conhecem o NASF-AB e oferecem possibilidade de execução ao seu processo de trabalho:

"eles [Agentes

Comunitários de

Saúde] têm uma mentalidade boa para entender o processo de trabalho, o

planejamento, os grupos, quando nós queremos implantar um grupo eles sempre nos apoiam e nós dependemos do apoio deles porque eles são a ponte entre nós e a comunidade"

(Profissional do NASF-

$\mathrm{AB})$.

De acordo com Andrade et al. ${ }^{9}$, o reconhecimento de uma equipe especializada de apoio pode abrir margens ao trabalho multidisciplinar ampliando o manejo sobre as peculiaridades da comunidade e suas necessidades, de forma a sanar ou minimizar os problemas emergentes.

Em Petrolina, ainda foi visto que o NASF-AB e as EqSF trabalham com hipertensos e diabéticos de forma a ampliar as responsabilidades de ambas as equipes, sendo uma categoria também favorável:

\footnotetext{
"Muitas vezes eu chamo e encaminho: 'óh, eu estou
} 
encaminhando um paciente, que eu acho que é isso, dá uma olhada pra mim'. Eles $[N A S F-A B]$ fazem, ele faz uns testes, óbvio que ele não segue o diagnóstico, porque ele sabe, até o limite dele, mas dá pra pegar e, olha é bem por aí, dá pra gente fazer isso, enquanto aguardamos uma consulta quilométrica com especialistas" (Médica ESF).

O trabalho multiprofissional baseiase na busca de respostas no núcleo de competência e responsabilidade de cada profissão, quando as questões advêm justamente da necessidade de sua extrapolação, por meio de práticas em campos comuns de competência e responsabilidade ${ }^{26}$. Sendo assim, o NASF$A B$ vem buscando reconhecer os limites de cada campo de saber. Para tanto, estabelecem nesse percurso parcerias que são na maioria das vezes indispensáveis para aumentar a resolutividade das demandas determinando outra categoria favorável do contexto político:

\footnotetext{
"Sempre quando eles $(N A S F-A B)$ podem, eles trazem pessoas tanto da área ligada com as faculdades, ou algum especialista num determinado assunto de saúde, do Centro de Orientação e Assistência Sorológica de Petrolina, ou até mesmo como agora que a gente vai fazer a horta veio o pessoal da AMA, que já é uma parte que mexe com plantas, essas coisas para analisar o solo. Então eles buscam parcerias" (Agente

Comunitário de Saúde).
}

A busca por essas parcerias também foi verificada nos estudos de Volponi et $a l .{ }^{27}$, Gonçalves et al. ${ }^{28}$ e Maciel et al. ${ }^{29}$, os quais verificaram que o NASF-AB estabeleceu as parcerias devidas estimulando, assim, reflexões sobre a atuação interdisciplinar e potenciais de mudança de práticas. Traduzidas em ações de alimentação e atividade física, essas práticas vêm sendo inovadas de forma lúdica, criativas e indutoras de relações significativas interprofissionais no âmbito das EqSF proporcionando outra categoria favorável:

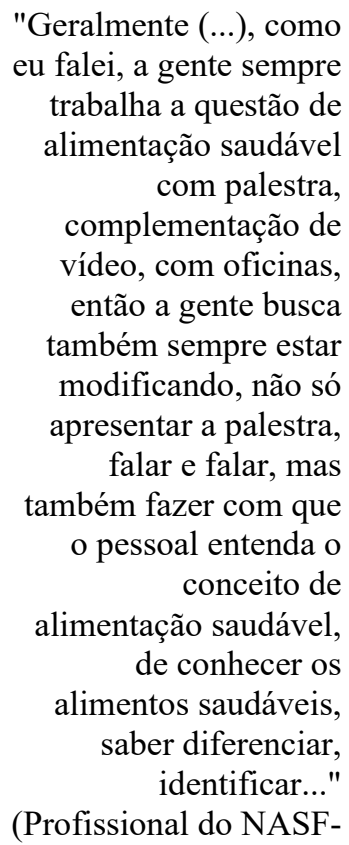

$\mathrm{AB})$.

O contexto político em Petrolina ao ser considerado como favorável demonstra como os atores desenvolvem suas ações de $\mathrm{A} / \mathrm{N}$ e $\mathrm{AF} / \mathrm{PC}$ no cotidiano das práticas do NASF-AB, revelando meios por vezes contraditórios à execução das mesmas. As possibilidades e oportunidades emanadas dessas relações poderiam suscitar a troca de saberes, discussões conjuntas e elaboração de planos de cuidados em comum acordo entre os profissionais.

Por sua vez, na abordagem estrutural, as estruturas físicas das unidades de saúde da família são desfavoráveis às ações do NASF-AB. No município de Petrolina existe também um arranjo organizacional na atenção primária denominado 
Núcleo ampliado de saúde da família e atenção básica (NASF-AB): um estudo avaliativo sobre suas ações com hipertensos e diabéticos NASF-AB: um estudo avaliativo

Extended family health and basic care center (nasf-ab): an evaluative study on your actions with hypertensive

Atendimento Multiprofissional Especializado (AME), o qual garante um espectro maior de atendimentos pela união de duas ou mais EqSF e um leque maior de serviços de cunho especializado e básico. Mas, até nessas AME, é visto que existem problemas de infraestrutura para realização das ações do NASF-AB:

$$
\begin{array}{r}
\text { "Quando a gente fala } \\
\text { hoje da composição de } \\
\text { AME que Petrolina } \\
\text { teve, tem um lado bom } \\
\text { e um lado ruim, porque } \\
\text { as AME foram } \\
\text { estruturas construídas } \\
\text { recentemente, então a } \\
\text { gente acredita que ela } \\
\text { tem um padrão } \\
\text { moderno com estrutura } \\
\text { para acolher esses } \\
\text { profissionais e esses } \\
\text { pacientes. Só que } \\
\text { quando a gente chega } \\
\text { na prática nós temos } \\
\text { AME ou própria UBS } \\
\text { que a gente não tem } \\
\text { nem pátio externo para } \\
\text { desenvolver as ações } \\
\text { de educação em saúde" } \\
\text { (Gestor do NASF-AB). }
\end{array}
$$

Quando se trata de estrutura física das unidades de saúde da família, esse é um fator tratado como negativo em alguns estudos realizados com o NASF-AB ${ }^{20,28,30}$. Martinez et $a{ }^{20}{ }^{20}$ apontam a unanimidade desse problema persistindo em diversos municípios brasileiros e que isso, além de suscitar descompassos na implantação do NASF-AB, é visto em suas origens pelo processo de subfinanciamento crônico do setor saúde.

Outra categoria do contexto estrutural desfavorável são os recursos financeiros para o NASF-AB. Estes são considerados escassos e, além disso, não são específicos para as ações de $\mathrm{A} / \mathrm{N}$ e $\mathrm{AF} / \mathrm{PC}$ :

“(...) na realidade a gente precisa aumentar o número de oferta do serviço, porém a quantidade de recursos para financiar em and diabetic Nasf-ab: a study evaluation serviço não aumenta" (Gestor do NASF-AB).

$$
\begin{array}{r}
\text { "Não de alimentação. } \\
\text { Não é só de } \\
\text { alimentação é de forma } \\
\text { geral, fisioterapia... pra } \\
\text { o NASF-AB de forma } \\
\text { geral. Como eu disse a } \\
\text { você que a gente } \\
\text { trabalha, que faz } \\
\text { fôlders, que faz } \\
\text { impressões é esse } \\
\text { recurso que a gente } \\
\text { tem, mas não tem } \\
\text { financiamento voltado } \\
\text { a isso não" } \\
\text { (Profissional do NASF- }
\end{array}
$$

$\mathrm{AB})$.

O uso eficiente de recursos locais, muitas vezes já disponíveis, bem como o financiamento direcionado para ações de promoção e prevenção em saúde são essenciais para o adequado controle das DCNT, entretanto, é válido salientar que a escassez de investimentos com recursos financeiros já é apontado nos estudos como fator que implica em descontinuidades do processo de trabalho com essas doenças ${ }^{31}$.

$$
\text { Ademais, outra categoria }
$$
desfavorável foram os vínculos profissionais. A realidade de contratualização de profissionais com vínculos empregatícios frágeis em Petrolina gera efeitos negativos que se somam aos da implicação anterior dos recursos financeiros:

"Interfere negativamente, porque a gente perde, digamos assim, o fio da meada, a gente vem com um grupo de profissionais trabalhando no ritmo, aí por algum motivo ele se afasta, pede pra sair, aí a gente tem que colocar outro que vai começar do zero (...)" (Direção de Atenção Básica). 
Reis et al. ${ }^{18}$ afirmam que o processo de trabalho dos profissionais de saúde do NASF-AB está relacionado às condições organizacionais nas quais os serviços disponibilizados estão dispostos, sendo esse fato um dos fatores determinantes para a manutenção dos padrões de qualidades das ações em saúde desenvolvidas.

Outra categoria desfavorável foi o ambiente de trabalho. Em Petrolina, as EqSF são diferentes em diversos aspectos (tamanho, tempo, composição de equipe, fluxos de trabalho, etc.), gerando um ambiente que suscita maneiras diversas da atuação multiprofissional para o NASF-AB:

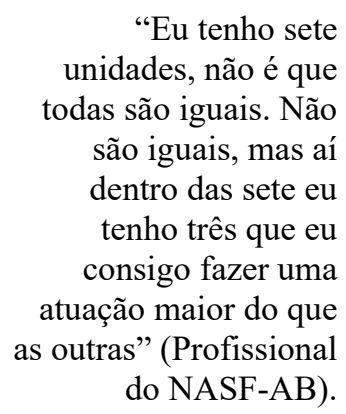

Sendo considerado como desfavorável, o contexto estrutural revela a necessidade de adaptações do NASF-AB enquanto organização de saúde para que haja uma performance mais efetiva das ações de $\mathrm{A} / \mathrm{N}$ e $\mathrm{AF} / \mathrm{PC}$ com usuários hipertensos e diabéticos como forma a otimizar a lógica de corresponsabilização e gestão integrada do cuidado requisitada para atuação dessa equipe multiprofissional.

A análise da totalidade das categorias permitiu inferir que aproximadamente $50 \%$ delas foram consideradas favoráveis à implantação do NASF-AB em relação às ações estudadas. Ao se analisar a importância de cada categoria no desenvolvimento das ações, é visto que em muitas delas existem evidências dessas ações serem executadas de maneira que institua o NASF-AB como elemento indutor de mudanças, embora reveladas fragilidades. Sendo assim, o contexto político e contingente final de Petrolina foi considerado como favorável.
No tocante à análise da relação entre o contexto e o grau de implantação do NASF-AB, percebeu-se que o conhecimento acerca do trabalho do NASF$A B$ pode ser um fator que favorece a implantação de alguns critérios do GI do processo, tais como "atendimento clínico compartilhado com os profissionais da equipe de saúde da família" e "participação em reuniões das equipes de saúde da família", pois existe o reconhecimento da importância de uma equipe especializada de apoio nas atividades da ESF com hipertensos e diabéticos.

Mediante a consulta compartilhada e a participação em reuniões de EqSF, o NASF-AB garante um momento em que há a troca de saberes entre os profissionais e incorporação de novos conhecimentos pelas equipes com proposições de atividades, projetos e pensamentos coletivos ${ }^{7,26}$. Assim, a existência de profissionais das equipes de referência que reconhece a atuação do NASF-AB e favorece a realização de atividades integradas, pode favorecer a implantação das ações de $\mathrm{A} / \mathrm{N}$ e $\mathrm{AF} / \mathrm{PC}$, contribuindo para a resolutividade das demandas surgidas pelos usuários hipertensos e diabéticos.

Articulação dos serviços de saúde através de parcerias interinstitucionais com instituições e entidades locais para $\mathrm{o}$ desenvolvimento das ações' foi outro critério implantado que pode estar relacionado ao contexto político no que tange aos mecanismos de parcerias para a realização de ações. Ao trabalhar com $\mathrm{A} / \mathrm{N}$ e AF/PC, o NASF-AB aborda fontes parceiras externas para ajudar nessas ações e essas articulações interinstitucionais são sustentadas por longo tempo. Tal fato corrobora com o que é referido por Assis et $a l .{ }^{32}$ os quais informam que a manutenção dessas parcerias é necessária para promoção da educação em saúde, o que tende a favorecer a incorporação gradual de novos hábitos de vida.

'Divulgação das informações sobre a temática' foi outro critério considerado implantado que possivelmente pode estar 
Núcleo ampliado de saúde da família e atenção básica (NASF-AB): um estudo avaliativo sobre suas ações com hipertensos e diabéticos NASF-AB: um estudo avaliativo

Extended family health and basic care center (nasf-ab): an evaluative study on your actions with hypertensive

sendo influenciado pelo contexto político ao se tratar da inovação nas práticas. Foi visto que as ações de $\mathrm{A} / \mathrm{N}$ e $\mathrm{AF} / \mathrm{PC}$ são desenvolvidas de forma a contemplar as necessidades do território e com caráter criativo e estimulador de novas práticas.

Assim sendo, o NASF-AB de Petrolina contribui para o fortalecimento da capacidade do cuidado das EqSF aos usuários hipertensos e diabéticos de maneira que estes recebem um espectro maior de informações de autocuidado, estilo de vida e adoção de hábitos alimentares saudáveis. A difusão de informações através de ações de educação em saúde e educação permanente refletem, então, o que o NASF-AB vem trazer de inovação no processo de trabalho das equipes, em outras palavras, proporcionando a produção de novos conhecimentos em ato, ao instituir a gestão coletiva do cuidado com vistas a uma clínica interdisciplinar comprometida.

Ao tratar da estrutura do NASF$\mathrm{AB}$ foi visto que sua implantação parcial configura fragilidades na disposição de itens necessários à execução dessas ações no município de Petrolina. 'Materiais para as ações', 'Materiais informativos', 'Computadores com internet', 'Equipamentos', 'Cadernos de Atenção Básica', 'Instrumento para realizar diagnóstico do território' foram critérios que estiveram parcialmente implantados no município.

A influência negativa do contexto estrutural de implantação do NASF-AB pode ser o fator que explique o baixo percentual obtido no GI. Os recursos financeiros para equipes NASF-AB revelam uma insuficiência de investimentos para suas ações e não têm direcionamento específico para financiá-las. Também é visto que as unidades de saúde da família não possuem equipamentos/materiais mínimos necessários para auxílio nessas ações, mesmo possuindo um arranjo organizacional diferenciado como as AME, e existe uma rotatividade no quadro de profissionais do NASF-AB. and diabetic Nasf-ab: a study evaluation

Investimentos para as equipes NASF-AB são referidos na literatura como qualificação profissional e contratação de recursos humanos ${ }^{31}$. A Política Nacional de Atenção Básica à Saúde $^{5}$ declara ser responsabilidade dos municípios e Distrito Federal o custeio de materiais e ações para o desenvolvimento das atividades mínimas descritas nas tarefas das ações dos diferentes profissionais que irão compor os NASF-AB. Assim, a contratação efetiva de profissionais, sua devida qualificação e distribuição de equipamentos para auxílio nas ações podem ser itens que devem ser manejados de forma profícua para as equipes NASF-AB, promovendo melhoras em torno de sua implantação em Petrolina.

As disposições normativas do NASF-AB requerem a aquisição de uma infraestrutura de suporte como, por exemplo, normativas locais de funcionamento do NASF-AB, apoiadores institucionais, transporte institucional, qualificação profisssional e educação permanente para o NASF-AB, dentre outros itens $^{24}$. Entretanto, Martinez et $a l .{ }^{20}$ ressaltam que há semelhanças estruturais importantes na maioria dos municípios brasileiros no que se refere às condições precárias de trabalho do NASF-AB, especialmente na infraestrutura, na falta de profissionais efetivos e materiais, as quais expressam a fragilidade da proposta no fortalecimento dos princípios da atenção básica e do seu papel de coordenação do cuidado na rede de serviços de saúde.

Considerando-se a premissa da interdisciplinaridade, a utilização dos espaços físicos não deve ficar restrita à lógica de espaços exclusivos para o NASF$\mathrm{AB}$ e, sim, ser compartilhado entre diferentes profissionais e atividades. Esse compartilhamento é o que vai permitir a construção de uma nova forma de trabalho em saúde centrada no usuário, com qualidade, resolutividade e equidade ${ }^{21}$.

Por fim, é claro salientar que estrutura e processo do NASF-AB para as ações de $\mathrm{A} / \mathrm{N}$ e $\mathrm{AF} / \mathrm{PC}$ possuem relações 
mais complexas com seus fatores tanto estruturais quanto políticos. Ao favorecer as ações, o contexto político abre a oportunidade do NASF-AB elaborar processos educativos, assistência clínicopedagógica e gestão integrada do território de maneira a contemplar a maioria dos critérios estabelecidos no seu ML; entretanto, o contexto estrutural não permite o êxito dessas ações em virtude de uma estrutura fragilizada que dificilmente sustenta essas práticas.

\section{Conclusão}

O GI total do NASF em relação à alimentação, nutrição e atividade física/práticas corporais no município de Petrolina, encontra-se parcialmente implantado, com uma pontuação percentual de $58,8 \%$.

Considerando sua implantação parcial em Petrolina, evidencia-se que há ações na dimensão estrutura e processo que não vem sendo executadas pelo NASF-AB, $o$ que pode estar favorecendo na fragmentação do cuidado ou não realização de algumas dessas ações que promovam hábitos saudáveis para o público com HAS e DM.

O contexto, apesar de ser considerado favorável, apontou diversos elementos que não favorecem a implantação dessas ações pelo NASF-AB, necessitando haver mudanças de ordem política e estrutural que visem fortalecer o papel do NASF-AB nessas temáticas frente ao cuidado em saúde prestado aos usuários hipertensos e diabéticos.

Ficou evidenciado que o estudo de análise de implantação ofereceu recursos metodológicos oportunamente válidos para a tentativa de verificar as oportunidades e fragilidades que o NASF-AB vem tendo no município de Petrolina ao se trabalhar com ações de alimentação/nutrição e atividade física/práticas corporais. Esses resultados poderão ser utilizados para subsidiar os gestores na tomada de decisão, promovendo as melhorias necessárias nas ações em saúde desenvolvidas pelo NASF-AB.

\section{Referências Bibliográficas}

1. BRASIL. Ministério da Saúde. Estratégias para o cuidado da pessoa com doença crônica. Brasília: Ministério da Saúde; 2014.

2. Bortoluz S, Lima LA, Nedel FB. Condições de saúde e utilização de um serviço de atenção primária em pacientes hipertensos e/ou diabéticos. Ciência \& Saúde 2016; 9 (3): 156-166.

3. Duncan BB, Chor D, Aquino EML, Bensenor IM, Mill JG, Schmidt MI, Lotufo, PA, Vigo A, Barreto SM. Doenças Crônicas Não Transmissíveis no Brasil: prioridade para enfrentamento e investigação. Rev. Saúde Pública 2012; 46 (Supl): 126-34.

4. Goulart FAA. Doenças crônicas não transmissíveis: estratégias de controle e desafios e para os sistemas de saúde. Brasília: OPAS; 2011.

5. BRASIL. Ministério da Saúde. Política Nacional de Atenção Básica. Brasília: Ministério da Saúde; 2012.

6. Amaral MN, Silva MEK. Atuação do nutricionista no núcleo de apoio à saúde da família: desafios da interdisciplinaridade no cuidado à saúde. Trab. Educ. 2015; 24 (2): 143-55.

7. Furtado GVM, Knuth AG. Núcleo de Apoio à Saúde da Família (NASF-AB) em Rio Grande/RS: percepções sobre o trabalho realizado pela educação física. Rev. Bras. Ativ. Fis. Saúde 2015; 20 (5): 514-23.

8. Pinheiro CTMA. Gestão das Doenças Crônicas: Implicações na Prática nos Cuidados de Saúde Primários - Unidade E [dissertação]. Lisboa: Universidade Aberta; 2009. 
Núcleo ampliado de saúde da família e atenção básica (NASF-AB): um estudo avaliativo sobre suas ações com hipertensos e diabéticos NASF-AB: um estudo avaliativo

Extended family health and basic care center (nasf-ab): an evaluative study on your actions with hypertensive and diabetic Nasf-ab: a study evaluation

9. Andrade LMB, Quandt FB, Campos DA, Delziovo CR, Coelho EBS, Moretti-Pires RO. Análise da implantação dos Núcleos de Apoio à Saúde da Família no interior de Santa Catarina. Saúde Transform. Soc. 2012; 3 (1): 18-31.

10. Hartz ZMA, Silva LMV. Avaliação em Saúde: Dos Modelos Teóricos à Prática na Avaliação de Programas e Sistemas de Saúde. Salvador: EDUFBA; 2005.

11. Champangne F. A análise de implantação. In: Brousselle A. Avaliação: conceitos e métodos. Rio de Janeiro: Fiocruz, 2011.

12. Prefeitura Municipal de Petrolina (PMP). Plano Municipal de Saúde 2014-2017. Petrolina: SMS; 2013.

13. Denis J, Champanhe F. Análise da implantação. In: Hartz, ZMA. Avaliação em saúde: dos modelos conceituais à prática na análise da implantação de programas. Rio de Janeiro: FIOCRUZ; 1997.

14. Ferreira VSC, Silva LMV. Intersetorialidade em saúde: um estudo de caso. In: Hartz ZMA, Silva LMV. Avaliação em Saúde: Dos Modelos Teóricos à Prática na Avaliação de Programas e Sistemas de Saúde. Salvador: EDUFBA; 2005.

15. Bardin L. Análise de Conteúdo. São Paulo: Edições 70; 2011.

16. Lira RC. Elaboração e validação de um questionário para avaliação da implantação do componente alimentação, nutrição e atividade física do NASF-AB em Pernambuco, PE [dissertação]. 2017. Recife: IAM/FIOCRUZ; 2017.

17. Fernandes JM, Rios TA, Sanches VS, Santos MLM. NASF-AB's tools and practices in health of physical therapists. Fisioter. Mov. (Online) 2016; 29 (4): 741-50.

18. Reis ML, Medeiros M, Pacheco LR, Caixeta CC. Avaliação do trabalho multiprofissional do Núcleo de Apoio à Saúde da Família (NASF-AB). Texto Contexto Enferm 2016; 25 (1): 01-09.

19. Fagundes AA. A atuação do nutricionista nos Núcleos de Apoio à Saúde da Família $(N A S F-A B)$ [tese]. Brasília: Universidade de Brasília; 2013.

20. Martinez JFN, Silva MS, Silva AM. O Núcleo de Apoio à Saúde da Família em Goiânia (GO): percepções dos profissionais e gestores. Saúde Debate 2016; 40 (110): 95-106.

21. Anjos KF, Meira SS, Ferraz CEO, Vilela ABA, Boery RNSO, Sena ELS. Perspectivas e desafios do núcleo de apoio à saúde da família quanto às práticas em saúde. Saúde Debate 2013; 37 (99): 672-80.

22. Souza TT, Calvo, M.C. Resultados esperados dos Núcleos de Apoio à Saúde da Família: revisão de literatura. Rev. Saúde Soc. 2016; 25 (4): 976-87.

23. Nascimento DDG, Oliveira MAC. Reflexões sobre as competências profissionais para o processo de trabalho nos Núcleos de Apoio à Saúde da Família. Mundo saúde 2010; 34 (1): 92-96.

24. Brasil. Núcleo de Apoio à Saúde da Família. Brasília: Ministério da Saúde; 2014.

25. Tesser CD. Núcleos de Apoio à Saúde da Família, seus potenciais e entraves: uma interpretação a partir da atenção primária à saúde. Interface Comun. Saúde Educ. 2017; 21 (62): 65-78.

26. Correia PCL, Goulart PM, Furtado JP. A avaliabilidade dos Núcleos de Apoio à Saúde da Família (ASF). Saúde Debate 2017; 41 (espec.): 345-59.

27. Volponi PRR, Garanhani ML, Carvalho BG. Núcleo de Apoio à Saúde da Família: potencialidades como dispositivo de mudança na Atenção Básica em saúde. Saúde Debate 2015; 39 (espec.): 221-31.

28. Gonçalves RMA, Lancman S, Sznelwar LI, Cordone NG, Barros, JO. Estudo do trabalho em Núcleos de Apoio à Saúde da Família (NASF-AB), São Paulo, Brasil. Rev. Bras. Saúde Ocup. 2015; 40 (131): 59-74. 
29. Maciel MS, Coelho MO, Marques LARV, Rodrigues Neto EM, Lotif MAL, Ponte ED. Ações de saúde desenvolvidas pelo núcleo de apoio à saúde da família - NASFAB. Saúde (St. Maria) 2015; 41 (1): 117-22.

30. Ribeiro MDA, Bezerra EMA, Costa MS, Branco CEC, Araújo Neto JD, Moreira AKF, Filgueiras MC. Avaliação da atuação do núcleo de apoio à saúde da família. Rev. Bras. Promoção Saúde 2014; 27 (2): 224-31.

31. Santos SFS, Benedetti TRB. Cenário de implantação do Núcleo de Apoio à Saúde da Família e a inserção do profissional de Educação Física. Rev. bras. ativ. fis. saúde 2012; 17 (3): 88-194.

32. Assis LC, Simões MOS, Cavalcanti AL. Políticas públicas para monitoramento de hipertensos e diabéticos na atenção básica, Brasil. Rev. Bras. Pesqui. Saúde 2012; 14 (2): $65-70$.

Como citar este artigo:

Gomes AS, Martelli PJL, Cesse EAP, Gomes MF, Santos RSAF, Chagas MBR, Costa JMBSC. Núcleo ampliado de saúde da família e atenção básica (NASF-AB): um estudo avaliativo sobre suas ações com hipertensos e diabéticos NASF-AB: um estudo avaliativo. Rev. Aten. Saúde. 2021; 19(67): 122-139. 